Article

\title{
Socio-Economic Inequity and Decision-Making under Uncertainty: West African Migrants' Journey across the Mediterranean to Europe
}

\author{
Mulugeta F. Dinbabo *, Adeyemi Badewa and Collins Yeboah \\ Institute for Social Development, Faculty of Economic and Management Sciences, University of the Western Cape, \\ Cape Town, South Africa, E-Mails: mdinbabo@uwc.ac.za (M.F.D), 3759258@myuwc.ac.za (A.B.), \\ collins399@gmail.com (C.Y.) \\ * Corresponding author
}

Submitted: 15 September 2020 | Accepted: 17 December 2020 | Published: 25 March 2021

\begin{abstract}
Understanding the nexus between poverty, inequality and decision-making under uncertainty in migrants' journeys across the Mediterranean Sea to Europe remains a significant challenge, raising intense scholarly debate. Several suggestions have been offered on how to reduce migrants' journeys across the Mediterranean Sea to Europe in several guises, including the formulation and implementation of proper social, political and economic policies in Africa. Despite all odds and challenges, migrants from Africa cross state boundaries and stay in transit state(s) for limited periods, en route the Mediterranean Sea to Europe. Underpinned by different migration theories and conceptual frameworks, our study applied a qualitative methodology to examine why migrants decide, under uncertainty, to cross the Mediterranean Sea from their countries of origin to the ultimate destinations in Europe. While focusing on the life experiences of purposively selected migrants from West Africa, the research seeks to address the underlying factors of irregular migration. The result of this empirical study clearly illustrates that limited access to opportunities, poverty and unemployment amidst precarious development challenges and the youth population bulge, exacerbate Africa's migration crisis. The study finally brings into focus empirical observations and provides suggestions for stakeholders' engagement in addressing African migration challenges.
\end{abstract}

\section{Keywords}

decision-making; Europe; inequality; Mediterranean Sea; migration; poverty; uncertainty; West Africa

Issue

This article is part of the issue "Decision-Making under Uncertainty: African Migrants in the Spotlight" edited by Didier Ruedin (University of the Witwatersrand, South Africa / University of Neuchâtel, Switzerland).

(C) 2021 by the authors; licensee Cogitatio (Lisbon, Portugal). This article is licensed under a Creative Commons Attribution 4.0 International License (CC BY).

\section{Introduction}

Migration in Africa, like other parts of the world, is a long-standing practice, spanning centuries. For diverse purposes, persons and groups in different categories, including students, highly- to low-skilled workers, artisans, nomads, professionals, refugees, asylum seekers and documented and undocumented migrants alike have been confronted with the choice of travelling within and beyond the continent. The diversity of mobility among Africa's population elucidates the significance of migration for Africa's development (Adepoju, 2000). This com- plex phenomenon has been propelled by diverse, overlapping and often shifting drivers (Carbone, 2017; Sithole $\&$ Dinbabo, 2016). Hence, analysing the drivers of migration requires understanding how migrants decide to migrate, where, when and by what means they decide to migrate, considering the limited information at their disposal and the inherent challenges in the process.

West Africa, as the name implies, is the westernmost part of Africa, bordered to the north by the Maghreb and North Africa, to the east by Central Africa and the Atlantic Ocean to the south and west respectively. It comprises 16 independent states, namely, Benin, 
Burkina Faso, Cape Verde, Côte d'Ivoire, The Gambia, Ghana, Guinea, Guinea-Bissau, Liberia, Mali, Mauritania, Niger, Nigeria, Senegal, Sierra Leone and Togo. Most of these states (except Mauritania) are members of the Economic Community of West African States (ECOWAS), an Abuja-based sub-regional intergovernmental organisation established on 28 May 1975 with the signing of the Treaty of Lagos. Officially francophone, anglophone and lusophone, the countries share similar native languages, culture, history and customs, and are bounded or separated by geographical features including vast lands, deserts (including the Sahara), mountains, savannahs and water bodies-rivers such as the Niger River, lakes and the Atlantic Ocean. Language and geographical features are two key factors that enhance intra-African mobility towards socio-economic integration. Beyond the considerable number of intra-African migrants and other non-African citizens crisscrossing West Africa, the countries of the region serve as both origin and transit for large numbers of migrants, particularly en route to Europe.

It was the objective of our research to better understand the nexus between poverty, inequality and migration decision-making under conditions of uncertainty and people's decisions of where to migrate given the limited information available to them. Our study aggregates the aspirations of irregular migrants from West Africa both in countries of origin and transit and how they maximise their ability to migrate, particularly to Europe, despite seemingly impossible odds or difficult barriers. The two-step models, that is, the 'ambition to migrate' and the 'ability to migrate,' critically explain why migrants make decisions without adequate information and how contradictory information affects decisions, highlights the critical factors of narratives and expectations, the influence of human biases (preferences) and bounded rationality on the ambitions to migrate (Carling \& Schewel, 2018). The subsequent sections provide a review of migration decision-making, the theoretical models, methodology and discussion of our findings. The final section offers recommendations and the general conclusions of our study.

\section{Why Do Immigrants Move To Countries in the Global North?}

Several arguments have been advanced on why immigrants move to countries in the Global North despite seemingly impossible odds (Baláž, Williams, \& Fifeková, 2016; Carbone, 2017; Dinbabo \& Carciotto, 2015; Smith, 2019). While expectations and narratives reflecting the preponderance of bounded rationality or biases shape ambitions to migrate, decisions to migrate are often affected by flawed and contradictory information. Nevertheless, the resort to maximise the capability to migrate in both countries of origin and transit deserves further examination. This article, therefore, undertakes a systematic review of literature involving the critical appraisal of significant views and theoretical models, and does a qualitative synthesis of our research findings.

The new decision space characterised by uncertainties has been unpacked in critical studies, including synthesis of uncertainty in analytical decision-making (Comes, Adrot, \& Rizza, 2017; Kale, Kay, \& Hullman, 2019). Technology, arguably, enables new forms of data aggregation and participation, and indeed presents a new stratum of complexity in decision- and policymaking, while not offering the end solution (Comes et al., 2017). This reflects the challenges of fragmented and 'post-factual' society and the contradictory nature of information, further amplified by complex socio-technical interdependencies and big data. Thus, the imperative of participatory approaches on decisionmaking in the big data era and enhanced roles of humanitarian actors is underscored. Accordingly, Kale et al. (2019) illustrate contemporary practices in applied research synthesis to match design challenges. The synthesis enables a feasible analytical comparison and shifts the emphasis from rationales of decisions to impacts on results. As established by revelations of canonical work, people's substitution of heuristic judgement for complex reasons characterises how they undermine uncertainty. Arguably, the desire to limit uncertainty leading to unwarranted expressions of certainty often produces negative decision-making consequences, individually or organisationally (Kale et al., 2019). Again, decision-making influenced by uncertainty may be infused by feelings of doubt or conflict, undermining the choice between alternative processes of actions. Thus, the synthesis of a possible analysis pattern, gathering information on the conviction behind choices, and the influences of interactive systems are significant to assessing an individual's judgement and decision-making under uncertainty.

Contrary to neo-classical theoretical assumptions, potential migrants contend with information overload and imperfect information in varying contexts (Baláž et al., 2016; Civljak, 2019). According to Baláž et al. (2016), the information overloads encompass the complexity of diverse socio-economic matters including crime, personal freedom, language barrier, health, climate and life satisfaction. In practice, the challenges of missing information are surrogated by existing knowledge or image of particular countries. Significantly, the study's experimental research methods enable proper identification of potential migrants' information search patterns. Secondly, it reflects on the decision weight attached to attributes of quality of life, especially economic vs non-economic criteria. Thirdly it highlights the individual's judgement in deciding on potential migration destinations under varying conditions of information (Baláž et al., 2016).

Similarly, individual preferences, socio-economic environments and social interactions are significant factors for predilection or choice of decision under uncertain conditions. These resonate where the desire for self-worth validation, career opportunities, a departure 
from stifling societal or social norms, and prospects for 'normal and happy lives' inspire decisions to migrate (Civljak, 2019). Accordingly, the influence of family members, the purpose of starting a family, potential boredom with unworthy lifestyles, the probability of repatriation and further migration elsewhere and favourable opportunities enhance the so-called Serbian Self-Initiated Expatriates (SIEs) decisions to live in the United States of America. The author underscores the significance of knowledge and transnational networks on the integration, acculturation and wellbeing of migrants amidst uncertainties. While migrants often live in metropolitan areas, transnational attachments induce opportunities among them, the SIEs' example reveals strong evidence of prospective professional and economic benefits through family connections and social networks as factors for migration decisions.

Moreover, migration networks, particularly social networks or location-specific social capital, influence migrants' decision-making (Haug, 2008), and by extension influence the decision to settle or return, particularly among highly-skilled first-time international migrants (Achenbach, 2017). The Bulgarian migrants' case illustrated in Haug (2008) reveals that social capital at the destination area positively influences emigration intentions and return migration. Contrariwise, social capital in the residence country or area may negatively influence return migration as illustrated in the study of Italian migrants in Germany (Haug, 2008). Migrants' actions reflect their larger social, economic, political and cultural environments, and are influenced by several factors. These environments influence their priorities and values, especially the aspects of employment and reproductive choices, settlement abroad and return migration (Achenbach, 2017). Therefore, the significant relations between economic and sociological facets of migration illustrate the impacts of social capital on migration decision-making and chain migration processes.

Furthermore, the current African migratory pattern towards Europe, compared with the 1970s influx of Mexicans to the United States of America, illustrates the influence of geographical proximity and adequate knowledge of the destination and routes (including irregular ones) shared between successful and prospective migrants; this significantly influences migrants' decisions against all odds. As a significant migrant reservoir, induced particularly by its youthful demography, Smith (2019) anticipates that over 100 million African migrants may cross the Mediterranean Sea to Europe over the next two generations. While projecting Europe's demographic decline and rapidly ageing population to enable it to accommodate some 50 million immigrants by 2050, pervasive poverty, unemployment and inequality are central to migration decisions in sub-Saharan Africa. Such decisions, he argued, are made possible by access to information and affordability of internet or $4 \mathrm{G}$ telephony by half of Africa's population against defying odds (Smith, 2019). Hence, through the value and perception of his larger environments, a migrant makes decisions (certain or uncertain) on how to achieve goals or solve problems. The decisions to settle or return are further impacted by a migrant's (individual) attributes or internal processes of his social and economic environments. Therefore, the knowledge of the above and the policy towards it, are capable of influencing decisions on migration by diverse actors and for different purposes. These can be understood from several theoretical assumptions.

\section{Theoretical Models}

Given the increasing intellectual efforts in international migration and its interconnecting issues, the theorisation of migration remains inadequate when compared with related fields of international transactions (Wickramasinghe \& Wimlartana, 2016). However, analysis of international migration may not be pinned down to a single theory due to the diversity and complexity of its domains. Thus, the theoretical perspectives of international migration and the categorisation of migration theories are conceived in the literature according to the origin of such theories, relevant discipline, patterns of migration, and the theories' application to modern contexts of migration. Wickramasinghe and Wimlartana (2016) conceive a level-based analysis of migration theories across three categories-micro-, macro- and meso-level. Such conception resonates across disciplines including anthropology, demography, development, economics, geography, and sociology which endeavour to theorise the causes and effects of migration, with special emphasis on economic, cultural, sociological, and geographic factors (Wickramasinghe \& Wimlartana, 2016).

Similarly, Kureková (2011) categorises migration theories into two sub-divisions: 'determinants of migration' and 'perpetuation of migration,' based on the subject analysis. Yet, systems theory, new economics theory, human capital theory, dual labour market theory and neo-classical theory are classified within the 'determinants of migration.' The theories classified under the 'perpetuation of migration,' include transnational migration, network theory and migration system theory. In the same vein, Huzdik (2014) sub-divides theories explaining the 21st century's migration process into four classifications. These include historical structural approach, behavioralist and equilibrium tradition, migration systems and theory of segmented labour. These, accordingly, are influenced by factors including wage differences, individual factors, economic globalisation, economic culture, institutional capacities to enhance migration, labour market disparities, and regional contrasts in the demand and supply of labour. The classifications above reflect on different assumptions and hypotheses, research objectives, interests, pursuits and decomposition of analyses. Therefore, the study is underpinned by the network theory and the decision-making theory, as both embrace the three level-based migration categories-micro-, macro- and meso-levels of analysis. 
The network theory explains the perpetuation of migration flows, based on the logic that potential migrants rely on current and former migrants, including their social networks and information provided in the destination countries towards cost maximisation and risk reduction (Castles, 2000). The theory underscores the meso-level factors - "social relations/ties among kinship or family groups, households, friendship circles, neighbourhoods and formal institutions" (Faist, 1997, p. 188). While migration is widely considered a process and not an event, and that macro analysis overlooks migrants and their families' agency and reduces their decisions to economic factors, especially labour in the Global North. Hence, decision-making theory encompasses the basic assumptions of rational actors and the rationality of perfect information. It centres on the following approaches: (1) normative, i.e., models of "how idealized persons think or act," (2) prescriptive, i.e., attempts to enhance the decision-making processes of persons and (3) descriptive, i.e., decision-makers' perceptions, constraints and processes of consideration (Achenbach, 2017, p. 49).

These illustrate the decision-making process of a migrant in respect of an individual's rationality, how (s)he processes a problem or concludes on a solution, and the timing and causality of the action birthed by the decision. Both micro and meso-level perspectives critically underscore rational explanations of cost maximisation and risk reduction (Achenbach, 2017). Considering the level-based analysis of understanding migration, the two theories integrate elements of micro, macro and meso-level categories in migration decision-making processes and outcomes. Therefore, this study understands migration decision as a process of the individual's rational thinking (primary element) and the permutations among integrated networks of persons, social groups and institutions (secondary element) towards the individual's objectives. The process of the individual's rational thought and behaviours channelled towards solving problems or prospective accomplishments and the push by the network of persons, social groups and institutions illustrate the interplay between the primary element (embodied in decision-making theory) and the secondary elements (epitomised by the network theory). This is critical to migrant's maximisation of costs, opportunities, information, resources and risks reduction in achieving desired outcomes.

\section{Methodology}

The research methodology employed a mix of secondary data analysis and field data collection to understand why migrants make decisions in conditions of uncertainty, to travel from West Africa, crossing the Mediterranean Sea to the ultimate destination of Europe. A purposeful selection of informants from West Africa, mostly from Ghana, the Gambia, Nigeria, Sierra Leone, including West African migrants in Libya, were interviewed using a semi-structured questionnaire. The interviews were conducted in different geographical locations and spatial settings (West and North Africa and Europe). In total, 25 interviews were conducted with refugees, asylum seekers and return migrants as well as with employees from the International Organization for Migration (IOM) and the United Nations High Commissioner for Refugees (UNHCR). As part of the field data investigation, a reformulation of the narratives presented by informants, taking into account the context of each case and the different experiences of each informant, was used. In general, the analysis helped in revising the primary data by researchers. Throughout the research process, data gathered from informants were treated with confidentiality and anonymity, as agreed during the consent process.

Given the current situation of the COVID-19 pandemic and the imperative of social distancing, online platforms/internet tools were used to collect data (telephone, WhatsApp and video conferencing facilities, such as Zoom) in the English language and then transcribed manually. The informants' particulars were replaced with pseudonyms to protect their identities. The findings were grouped thematically across four headlines: decision-making under uncertainty (cost maximisation and risk reduction), ability to migrate, sourcing information and expectations and prospects for migration, as deduced from both the literature and primary data. A framework analysis was applied in terms of identifying a thematic framework, coding, charting, mapping and interpretation. This was done manually using six iterative processes, i.e., data familiarisation, coding, themes identification, themes review, labelling and repetition (of processes) to produce coherent explanations. Findings were substantiated with purposely selected direct quotes. To arrive at conclusions, the degree of correlation between the information gathered and the theoretical/conceptual framework was used as a guiding principle and parameter.

\section{Findings and Analysis}

\subsection{Decision-Making under Uncertainty: Migrants' Rationality for Cost Maximisation and Risk Reduction}

Decision-making under uncertainty is a consequence of several choices and a set of different outcomes. This reflects on the rationality of cost maximisation and risk reduction (Clemens, 1996; Pate-Cornell \& Dillon, 2006). To investigate issues about migrants' decision-making under uncertainty or risk to leave the country of origin, informants were asked what/who influenced their decisions to migrate and if any customs or beliefs enhanced their decisions to migrate. Nearly $70 \%$ of respondents revealed that Libya's 'pull' factor has historically been its potential for employment opportunities and geographic location (accessibility to Europe). Many respondents also indicated that Libya served as a popular destination for 
migrants seeking different types of opportunities. Some of those interviewed indicated clearly that the opportunities for economic gain remain a reality for them and Libya still presents a viable option for migration. Several informants suggested that the road to Libya is marked by a long desert crossing, frequently facing hunger and thirst, leading to death in precarious conditions. Some migrants were abused by smugglers who were supposed to ensure their safe passage, but were notorious for robbing them of their belongings and 'dehumanising' their 'customers.' Much of the time migrants are at risk, not just from smugglers' trafficking them but also from arrest and detention by the authorities of the different transit countries. The final stage of the journey is the boat ride across the Mediterranean Sea from the Libyan coast to southern Italy, Malta and elsewhere. The boat trip is a common experience of migrants of all nationalities travelling through Libya toward Europe. These underscore the 'pull factor' of travelling to access opportunities, as reasons for decision-making in uncertain conditions.

The informants alluded to the socio-economic circumstances in their countries, e.g., youth unemployment, poverty, inequality and difficulties in accessing opportunities, as reasons for uncertain decision-making. Hence, migrants make unpredictable choices in their lifetime to meet the daily requirements of family, individual and community members. To them, this does not require careful planning to travel from the countries of origin to the country of destination, and without thorough consideration to begin a long journey. A similar pattern, as captured in the following quotes, was recorded amongst migrants from Nigeria, Sierra Leone and the Gambia:

I did not inform anyone before travelling. I am a guy who rarely discusses my big steps in life with people. I made the decision, gathered some money and travelled to Niger. It was there I met some Nigerians of like minds to travel by road to Europe. (James, Nigerian migrant in Tripoli, Libya)

Sometimes you must decide in a haste! Certain decisions require careful planning, but when it comes to travelling, you need to move. You have to take risks, else nothing good will come your way. (Favour, Sierra Leonean migrant in Tripoli, Libya)

I know it is dangerous to travel by road to Libya but man must survive! When starvation is staring you in the face, nobody will decide for you, but do it by force! (Muhammed, Gambian migrant in Misrata, Libya)

I was not certain of any danger, I made a daring move without a prior plan. I was ready to face death and survive [rather] than to starve to death. (Fred, Nigerian migrant in Malaga, Spain)

Overall, migrants do not consider the challenges of irregular travel. However, several respondents, especially migrants from West Africa, reported they take individual decisions under uncertainty to risk the long trip, with the final destination (Europe) uppermost in their minds. In this respect, the geopolitical location of Libya makes it a transit route for migrants moving to Italy and other states in Europe. However, most journeys end in disaster, with deaths of family members, acquaintances and fellow travellers:

I have been to Libya since 9 January 2020, I arrived at about 7:00 PM because I wanted to cross the sea to Europe [Germany]. But I could not continue due to the Coronavirus pandemic. (Uche, Nigerian migrant in Misrata, Libya)

I will move after some time. Libya is not safe. They are killing people now and then. Foreigners are vanishing without a trace.... l am just gathering some money to cross the sea to Italy; that was my plan before coming here. (Favour, Sierra Leonean migrant in Tripoli, Libya)

Indeed, some respondents reported that they fled to Libya after escaping imprisonment or shortly after release from custody, mostly for a limited duration in various Libyan and Algerian towns. Despite these uncertainties, customs or values often motivated respondents' decisions to migrate, including out-migration to enhance their situations towards achieving their final goal. In the context of Ghana, there is a tradition or belief that a man is not expected to sit on his 'buttocks' but to walk! Respondents suggested they were born to make tough decisions and migration is one such decision. Parents usually advise youths (in Ghana and Nigeria) to settle elsewhere and start a new life away from the family home or hometown if they want to be happy or successful. This rationalisation, according to the respondents, has long-term impacts on those who fail to travel but live in their groups and fail to succeed. This situation causes many youths to look for alternatives in uncertainties and seek to travel overseas through Libya in search of a better life.

Some informants of Nigerian origin maintained that the need to be influential in their communities is among the reasons migrants resort to irregular means of travelling. Others see migration as part of the human tradition and link it to the Biblical Noah. According to one of them:

Human beings started migrating in the time of Noah; hence, it is an age-long event and a part of our tradition. (Uche, Nigerian migrant in Misrata, Libya)

On the whole, West African migrants interviewed were youths, whose socio-economic problems and the perceptions of El Dorado in Europe propelled their decisions to leave their countries of origin amid uncertainties. Moreover, as mentioned by several informants, the absence of information, miss-perception about Europe and social/peer pressures enhanced decisions in uncer- 
tain conditions. Following the Valletta Summit in 2015, African and European leaders unequivocally acknowledged the benefits of well-managed migration and committed to developing common strategies to address its inherent challenges (Dinbabo \& Badewa, 2020). In this regard, the International Organization for Migration is implementing a project funded by the European Union Emergency Trust Fund for Africa to strengthen the protection and reintegration of migrants. As part of this initiative, an awareness-raising strategy is being developed to inform returning migrants about the possibilities of assistance and protection under the EU-IOM Joint Initiative. This strategy will also inform potential migrants, communities of origin and the public about the dangers of and the alternatives to irregular migration. The awarenessraising activities implemented under the project aim to ensure that migrants make informed migration decisions. In this regard, the IOM plays an important role in assisting return migrants and providing support for the needy across all West African countries, including Equatorial Guinea and Mauritania.

\subsection{Ability to Migrate}

This is defined as a set of tasks that an individual, community or a system are potentially able to undertake at a certain performance level with the use of internal or external resources (Robeyns, 2003). To understand and analyse migrants' ability to migrate, respondents were asked about their conditions when they considered outmigrating, what form of risks they took to facilitate their travel, what role the family or community played in supporting their travel abroad, and how they maximised resources amid challenges while in transit. From the available information, respondents decided to migrate using various means to facilitate their travel to Europe. Several migrants confirmed that the ability or resources to migrate include access to finance, a valid passport for international travel, the connection with smugglers of migrants across borders among others. These means are often sourced from migrants' savings, financial resources received from family members, remittances from successful relations and friends abroad and their connections. Some informants highlighted as follows:

I was a businessman; I was making it very well in Ghana. The 5,500 USD paid was my own money. I didn't ask anyone for help. (Quarm, Ghanaian migrant in Algeria)

I used my entire savings. Now the business has collapsed. I don't know how I am going to start again when I finally return to Nigeria. It's a dangerous thing I did. I pray nobody finds [themselves] in this situation. (Jude, Nigerian migrant in Benghazi, Libya)

My brother assisted me to pay for my travel. He gave me 1,000 cedis equivalent to 171.09 USD]. At the community level, I can only mention my friend's support to get to Libya. (Kofi, Ghanaian migrant in Benghazi, Libya)

My decision to travel to Libya was influenced by a friend. He had a brother in Libya who had invited him to join him in Libya. When he told me, and considering that things were difficult in Accra, I decided to join him. I informed my older brother who supported me financially to embark on the journey. My parents never approved of this, so we decided not to inform them. (Kyeremeh, Ghanaian migrant in Sirte, Libya)

For many migrants, the long journey to Europe, by road and sea, is fraught with risks and life-threatening circumstances. The journey usually consists of three stages: a desert crossing to the Maghreb to the Libyan border; heading from the border into the northern coastal towns within Libya; and a boat trip across the Mediterranean Sea to Italy. The migrants usually give a large amount of money to traffickers at all phases of the journey to allow them to reach their destinations. Some of the migrants were adequately prepared, while some were less prepared for eventualities. This is captured in the following testimonies:

I took a loan from the bank [3,000 USD] and sold my barbing shop for 2,500 USD in addition to my savings [1,500 USD], altogether 7,000 USD, to facilitate my travel to Spain. As we speak, I am still sending money home to settle the bank loan I took. (Yaw, Ghanaian migrant in Huelva, Spain)

Because of previous experience, I knew my way out and what to expect in the desert, so I planned very well for it, had all my food, hid my money on me because you could easily meet bandits on the way and they would take everything from you. I also arranged to pay the bandits or soldiers we met on the way. (Kyeremeh, Ghanaian migrant in Sirte, Libya)

I did not know a lot of things there, so I didn't make proper arrangements for eventualities. While in Niger, we were attacked by some robbers and they took everything from us. I nearly stopped travelling to Libya. I had to call my wife to send some money to pay for my transportation to Libya. (Martin, Nigerian migrant in Sirte, Libya)

These testimonies reveal that individuals' savings, support from household members and bank loans strengthened the migrants' capability to travel amidst uncertainties. While financial remittances were also an important factor, the past experiences, connections with 'travel agents' and the availability of professional smugglers in transit routes thus bolstered irregular migrants' capability to travel. 


\subsection{Sourcing Information}

The objective of investigating the sources of information at migrants' disposal, is to ascertain how information influences the decision to migrate. Hence, informants were questioned about the knowledge or impressions of their destination countries, the proposed route, and information about transit/destination countries. This also included information about their household/family members and friends, resident in Europe. Respondents indicated that the existence of social media and other social networks including WhatsApp, Facebook, Instagram, Twitter, migrants' connection and relatives abroad and other technologies facilitated the sharing of opinions. Information shared through the building of virtual networks and communities aided migrants' decisionmaking. Accordingly, technologies provided them with quick means to communicate with family members, friends and acquaintances. Migrants usually engage with social media via smartphones, web-based software or web applications when sourcing information on travel to Europe. A range of views expressed by respondents include the following:

Significantly, the network I built with my friend helped in shaping my life. Some people rely on Facebook and other social media to get a 'connection man' to support their travel abroad. I did not do that, thanks to my friend. (Yaw, Ghanaian migrant in Huelva, Spain)

My relationship with my friend helped a lot in the sense that he guided me through the decisionmaking process, who to contact on the way, and even at the final destination in Libya. My transit was fruitful, thanks to my friend. (Kyeremeh, Ghanaian migrant in Sirte, Libya)

Social media? Look, the 'burgars' [i.e., local name for travellers in Ghana] will usually take pictures in a very nice environment and sometimes in front of a beautiful car and share on Facebook. These are beautiful images of fulfilment you would want to experience.....Any time I see those pictures, I feel like I am the one there, and that influenced my decision. (Quarm, Ghanaian migrant in Algeria)

Social media has informed my decision. The only contact person we had in Libya was my friend's brother. (Christian, Ghanaian migrant in Benghazi, Libya)

\subsection{Expectations and Underlying Prospects for Migration}

To assess the expectations and motivations for migrating, informants were asked different questions. These included their knowledge of the destination countries' opportunities, goals they planned to achieve or problems they proposed to solve, by migrating to the destination countries, as well as their possible decision to return. Well above 80 percent of the respondents identified the search for survival and greener pastures as the major factor for millions of youths, including women from parts of West Africa, to risk possible death in their attempts to cross the Maghreb and the Mediterranean Sea, en route to Europe. Such individual decision-making under uncertainty, despite the dangers associated with leaving the country of origin, is fuelled by the lack of economic and employment prospects, political turmoil, unfavourable social relations, peer pressure, misunderstandings, and the quest for a better future. Such factors have led to a large proportion of the population looking for alternatives to better livelihoods for themselves and their families (Smith, 2019). Interestingly, most of the migrants planned to return to their countries of origin. The following comments reflect some of these perspectives:

Job opportunities! I still have that image todayI believe there are opportunities in Europe. Due to the work prospect, I paid a huge amount to the agent. I was convinced that once I reached Italy I would be able to make it in, multiple times. (Quarm, Ghanaian migrant in Algeria)

The fact that there are jobs for people in the construction sector, influenced my decision. I was not worried about the dangers-my interest was in job opportunities. (James, Nigerian migrant in Tripoli, Libya)

I knew Niger is a transit country for most Africans travelling to Libya. The fact that there will be a lot of people coming here to start their journey influenced my decision to come back to start my business. Because, once people transit through here, I believe they would need some items to take along. (Fred, Nigerian migrant in Misrata, Libya)

Some of the responses on return migration include:

Oh yes! I will go back one day to Ghana. We need to go back to show that at least we have also made it in life. (Yaw, Ghanaian migrant in Huelva, Spain)

Yes, I want to set up my own business in Ghana, so I would like to go back when I made enough money. (Kyeremeh, Ghanaian migrant in Sirte, Libya)

To Nigeria? Not now, my brother! Maybe in the future when I feel that I have made enough [money]. But to go back to Nigeria this time, ah ah. (James, Nigerian migrant in Tripoli, Libya)

There is no going back for me. I have suffered a lot there! It is better here for me than to go back to the stress in The Gambia. (Muhammed, Gambian migrant in Tripoli, Libya) 
The above empirical evidence clearly shows that migrants' decision-making under uncertainty to cross the Mediterranean Sea to Europe is based on expectations of escaping poverty, and hopes of a better life. Accordingly, the journeys undertaken by large numbers of migrants from West Africa to Europe usually take place by boat, across the Mediterranean Sea. On these long journeys to Europe, most migrants are at risk of serious injury, human rights abuses, or even death, during these perilous trips of desperation. The fragility of the Sahel states also heightens uncertainty due to conflict or militant insurgency and militarisation of migrants routes by local and foreign-backed mercenaries most especially in Libya and Niger. The growing insecurity and political instability have contributed to the lack of opportunities for young African populations. This brings to light how such conditions create the means for traffickers and smugglers of migrants to operate along viable transit routes in the Sahara, the Maghreb and through the Mediterranean. Consequently, the need to migrate significantly explains the sustained movement of Africa's youths through the Sahara despite the inherent dangers.

\section{Conclusion}

The foregoing illustrates that socio-economic inequity, most especially the lack of opportunities and expectations of a better life underlies decision-making in uncertainty among African migrants. This phenomenon echoes Smith's (2019) postulation that limited access to opportunities, poverty, inequality and unemployment amidst precarious development challenges and youth population bulge, exacerbate Africa's migration crisis. The empirical evidence provided by West African migrants to the Maghreb (Libya and Morocco) and Europe, further underpinned by the Decision-making and Network Theories, reveal that factors external to migrants, the ability (resources) to migrate, sources of information/networks, and the prospects/expectations of a migrant are among the crucial social, cultural, economic and political dynamics that uniquely mix to influence every migrant's decision-making process differentially. The external factors impacting on migrants include customs/beliefs; family; the migrant's societythe 'push' factors-and the characteristics of the destination country-the 'pull' factors (Dinbabo \& Badewa, 2020; Dinbabo \& Nyasulu, 2015). The migrant's ability factors may include financial capacity; household support, including remittances; ability to take risks; plans for eventualities; and resilience against unforeseen circumstances particularly in transit or destination countries. This also encompasses families' support, communication and concerns for migrants' wellbeing towards risk reduction and cost maximisation (Pate-Cornell \& Dillon, 2006).

Moreover, sourcing information (about the transit routes, destination and means of travel) may be influenced by social media, and social networks, including family, friends, returnees, and professional migration agents. Finally, expectations or motivations of migrating may be shaped by the impressions of a destination country and the opportunities it provides, the role of transit countries, the impact on return migration and accomplishing (the migrant's) goals. Hence, individuals' judgement to decide on potential migration destinations varies according to diverse information, support systems and prospects for opportunities (Baláž et al., 2016). In other words, a migrant's reflection of his larger socio-cultural, political and economic environments influence his priorities and values, choices of settlements and prospects for return (Achenbach, 2017). The above level-based analysis of migration decisionmaking under uncertainty incorporates the micro-level, macro-level and meso-level factors of migration decisions, underscored by the combination of both network theory and decision-making theory.

The study acknowledges that Africa's chaotic migration policy environment, coupled with regional security threats in the Sahel-Maghreb corridor and the European Union external borders policy, exacerbate irregular migration practices across the Mediterranean Sea to Europe. Nevertheless, the phenomenon cannot be checked without the proper understanding of its underlying factors and political-economy. This is because prominent individuals, traditional authorities, state security agents and private enterprises, particularly banks, migrant smugglers, transporters and shelter providers are involved. Therefore, the transformation of irregular migration routes and the entire region into a Special Economic Zone, tourism and educational hub can change the narratives and thus address the region's growing human security challenges and youth disempowerment. Indeed, critical stakeholder engagement towards addressing poverty and inequality, regional insecurity and migration crisis should be entrenched in the region. These may be mediated among national migration governing agencies, NGOs and civil societies and intergovernmental organisations-e.g., the African Union, ECOWAS and the European Union-as well as relevant UN agencies on migration, refugees and development-e.g., the IOM, the UNHCR and the United Nations Development Programme. The abovementioned capacity-building will promote intra-regional mobility such as (seasonal) labour migration, crossborder trade, mixed migration and remittances for development in the spirit of the African Continental Free Trade Area, and enhance the implementation of the African Union's Agenda 2063 and its Migration Policy Framework for Africa.

\section{Acknowledgments}

We gratefully acknowledge the efforts of respondents who took valuable time away from their day to participate in the research. Without them this empirical study would not have been possible. 


\section{Conflict of Interests}

The authors declare no conflict of interests.

\section{References}

Achenbach, R. (2017). Return migration decision making: Theoretical considerations. In R. Achenbach (Ed.), Return migration decisions: A study on highly skilled Chinese in Japan (pp. 27-77). https://doi.org/10.1007/978-3-658-16027-2

Adepoju, A. (2000). Issues and recent trends in international migration in sub-Saharan Africa. International Social Science Journal, 52(165), 383-394.

Baláž, V., Williams, A. M., \& Fifeková, E. (2016). Migration decision making as complex choice: Eliciting decision weights under conditions of imperfect and complex information through experimental methods. Population, Space and Place, 22(1), 36-53. https://doi.org/ 10.1002/psp.1858

Carbone, G. (2017). Between a rock and a hard place: Why Africans migrate. In G. Carbone (Ed.), Out of Africa: Why people migrate (pp. 13-30). Milan: ISPI.

Carling, J., \& Schewel, K. (2018). Revisiting aspiration and ability in international migration. Journal of Ethnic and Migration Studies, 44(6), 945-963. https:// doi.org/10.1080/1369183X.2017.1384146

Castles, S. (2000). Ethnicity and globalization: From migrant worker to transnational citizen. London: Sage.

Civljak, K. (2019). Choice under uncertainty: The settlement decisions of Serbian self-initiated expatriates in the United States. Journal of Intercultural Management, 11(1), 47-79. https://doi.org/10.2478/joim2019-0003

Clemens, R. T. (1996). Making hard decisions. Belmont, CA: Duxbury Press.

Comes, T., Adrot, A., \& Rizza, C. (2017). Decision-making under uncertainty. In K. Poljanšek, M. Marin Ferrer, T. De Groeve, \& I. Clark (Eds.), Science for disaster risk management (pp. 404-440). Ispra: Joint Research Centre.

Dinbabo, M. F., \& Badewa, A. S. (2020). Monitoring migration policy frameworks, treaties and conventions for development in Africa. Journal of African Union Studies, 9(1), 23-49.

Dinbabo, M. F., \& Carciotto, S. (2015). International migration in Sub-Saharan Africa (SSA): A call for a global research agenda. African Human Mobility Review, 1(2), 154-177.
Dinbabo, M., \& Nyasulu, T. (2015). Macroeconomic determinants: Analysis of 'pull' factors of international migration in South Africa. African Human Mobility Review, 1(1), 27-52.

Faist, T. (1997). The crucial meso-level. In T. Hammar, G. Brochmann, K. Tamas, \& T. Faist (Eds.), International migration, immobility and development: Multidisciplinary perspectives (pp. 187-217). Oxford and New York, NY: Berg.

Haug, S. (2008). Migration networks and migration decision-making. Journal of Ethnic and Migration Studies, 4(4), 585-605. https://doi.org/10.1080/ 13691830801961605

Huzdik, K. (2014). Migration potential and affecting factors in Hungary in the first decade of the 21st century (Unpublished Doctoral dissertation). Szent István University Gödöllő, Hungary.

Kale, A., Kay, M., \& Hullman, J. (2019). Decision-making under uncertainty in research synthesis: Designing for the garden of forking paths. In Proceedings of the $2019 \mathrm{CHI}$ Conference on Human Factors in Computing Systems. New York, NY: Association for Computing Machinery. https://doi.org/10.1145/ 3290605.3300432

Kureková, L. (2011). Theories of migration: Conceptual review and empirical testing in the context of the EU East-West flows. Paper presented at the CReAM Interdisciplinary Conference "Migration: Economic change, social challenge," University College London, UK.

Pate-Cornell, M., \& Dillon, R. L. (2006). The respective roles of risk and decision analyses in decision support. Decision Analysis, 3(4), 220-232.

Robeyns, I. (2003). The capability approach: An interdisciplinary introduction. Amsterdam: Department of Political Science and Amsterdam School of Social Sciences Research, University of Amsterdam. Retrieved from https://commonweb.unifr.ch/artsdean/pub/ gestens/f/as/files/4760/24995_105422.pdf

Sithole, S., \& Dinbabo, M. (2016). Exploring youth migration and the food security nexus: Zimbabwean youths in Cape Town, South Africa. African Human Mobility Review, 2(2), 512-537.

Smith, S. (2019). The scramble for Europe: Young Africa on its way to the old continent. Cambridge: Polity Press.

Wickramasinghe, A., \& Wimlartana, W. (2016). International migration and migration theories. Social Affairs, 1(5), 13-32. https://doi.org/10.1142/97898 12773890_0026

\section{About the Authors}

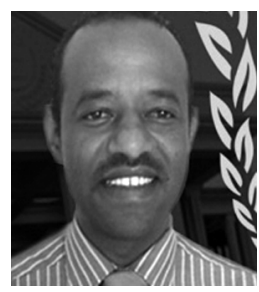

Mulugeta F. Dinbabo (Professor) obtained his Doctoral Degree in Development Studies. His research interest includes migration and development, diaspora studies, migration policies and remittances. He has built a strong research ethic and published extensively in local and international peer-reviewed journals. Professor Dinbabo is the Chief Editor of the African Human Mobility Review (AHMR), an accredited journal by the South African Department of Higher Education and Training (DHET). 


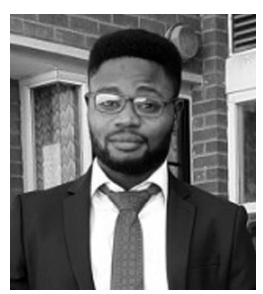

Adeyemi Badewa (PhD) obtained his Doctoral Degree in Development Studies from the University of the Western Cape and a Master Degree in History and Strategic Studies in Lagos. He previously taught course on international relations and comparative governance at the Department of Political Studies, University of the Western Cape. He specialises in human security, regional development and multilateral governance, with interest spanning the fields of international relations, development, migration, and peace and conflicts studies.

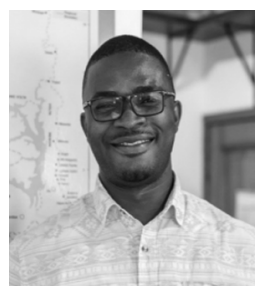

Collins Yeboah holds a double Master degree in Development Management from Ruhr University, Bochum, Germany, and in Development Studies, University of the Western Cape, South Africa. He earned his Bachelor of Arts (BA) degree in Geography and Resource Development with Sociology from the University of Ghana. He is currently pursuing his PhD in Development Studies at the University of the Western Cape, South Africa. His interests are in migration, remittances and poverty reduction strategies. 